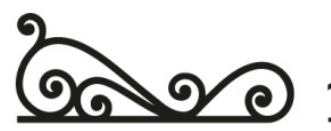

$12^{\circ} P \& D 2016$

CONGRESSO BRASILEIRO DE PESQUISA

E DESENVOLVIMENTO EM DESIGN

\title{
PARCERIA DO PROJETO DE EXTENSÃO UNIVERSITÁRIA LABORATÓRIO DE DESIGN SOLIDÁRIO E A ASSOCIAÇÃO CORNÉLIA VLIEG: APLICAÇÃO DO DESIGN NA PRODUÇÃO DE MOSAICOS
}

\author{
Guilherme Souza Prado Lourenção \\ Universidade Estadual Paulista "Julio de Mesquita Filho" \\ Cláudio Roberto y Goya \\ Universidade Estadual Paulista "Julio de Mesquita Filho" \\ goyaclaudio@hotmail.com
}

Resumo: Este artigo é parte de um projeto de assessoria em andamento e tem como objetivo descrever a parceria realizada entre o projeto de extenção Labsol, e a Associação Cornélia Vileg na produção da oficina de mosaicos do NOT - Núcleo de oficinas de trabalho da associação Cornélia Vileg. A Associação se trata de uma organização sem fins lucrativos que atua na reabilitação psicossocial de pessoas que sofrem de transtornos mentais através do trabalho em oficinas que funcionam como espaços de inclusão social. Conhecendo o trabalho do Labsol houve a procura do projeto para o desenvolvimento de novas peças visando o aumento da rentabilidade da produção. O Labsol por sua vez tendo como base teórica os conceitos de Sustentabilidade, Ecodesign e Economia Solidária e os autores Singer, Vezzoli, Manzini e Baxter está discutindo e entendendo a necessidade da proposta de um redesign das peças da Oficina de Mosaico, compreendendo sua importância enquanto patrimônio cultural, agregando valor a sua linha de produção e prezando sua inserção no mercado.

Palavras Chave: Sustentabilidade, Design Solidário, Design Social, Ecodesign, Artesanato, Mosaico.

Abstract: This article is part of an assistance project in progress and aims to describe the partnership held between Labsol extension project, and Cornelia Vileg Association in the workshop production of its NOT-Núcleo de oficinas de trabalho mosaics workshops. The Association is a non-profit organization engaged in psychosocial rehabilitation of people suffering from mental disorders by working in workshops that function as places for social inclusion. Knowing the work of labsol there was the calling of the project to develop new peaces in order to increase the profitability of production. The Labsol itself uses as theoretical basis the concepts of Sustainability, Ecodesign and Solidarity Economy and the authors Singer, Vezzoli, Manzini and Baxter and is discussing and understanding the need for the proposal for a redesign of the Mosaic Workshop peaces, being 
awared of its importance as cultural heritage, adding value to its production line and valuing their insertion in the market.

Keywords: Sustainability, Design Solidarity, Social Design , Ecodesign , Crafts, Mosaic .

\section{INTRODUÇÃO}

Esse é um projeto de caráter descritivo que tem o objetivo de fazer um retrato de como vem sendo a atuação do projeto Laboratório de Design Solidário, Labsol, do Departamento de Design da Instituição de Ensino Superior, em Relação à Associação Cornélia Vileg. Mas se faz necessário deixar evidente desde já que o Labsol, se trata de um projeto de extensão do departamento de design da Universidade Júlio de Mesquita filho, Unesp Bauru que trabalha com design solidário dando apoio à comunidades carentes na produção artesanal a partir da aplicação do design utilizando como tripés a sustentabilidade, a economia solidária e a não agressão ao meio ambiente e que a Associação Cornélia é uma instituição sem fins lucrativos que atua na reabilitação psicossocial de pessoas que sofrem de transtornos mentais através do trabalho em oficinas que funcionam como espaços de inclusão social.

Ao longo do texto será feita em mais detalhes uma caracterização de ambos os projetos e de como vem sendo a produção de mosaicos antes e depois dessa interação. Vale elucidar que a procura do Labsol ocorre a partir da própria associação que tinha a intenção de melhorar a rentabilidade nas atividades dessa e de outras oficinas, e que o Labsol trabalhou, em várias das 14 oficinas que o NOT possui, mas que esse texto tem a intenção de aprofundar apenas nessa oficina de mosaicos utilizando de descrição e imagens para que se exponha uma analise completa da situação.

É igualmente relevante dizer que toda a produção aqui analisada está ocorrendo após revisão bibliográfica, envolvendo áreas como o design, pesquisa cultural e de mercado, e química/ambiental, utilizando os tripés do LabSol que tem em sua base conceitual a Sustentabilidade, o Ecodesign e a Economia Solidária e o Design Social utiliza-se a Metodologia do Projeto em Design do Produto (BAXTER, 2011) procurando suprir a demanda da Cooperativa e o desenvolvimento de novos produtos tendo em conta as características socioculturais em que se insere o NOT.

\section{DESENVOLVIMENTO}

O Projeto de Extensão Labsol, Laboratório de Design Solidário, pertencente ao departamento de Design da Instituição de Ensino Superior, possui como principal proposta, o desenvolvimento de ações conjuntas entre o design e o artesanato como patrimônio cultural. O Labsol trabalha partindo de um tripé constituído pelos conceitos de Sustentabilidade (MANZINI, E.; VEZZOLI, 2008), Ecodesign (MARLET, 2005) e Economia Solidária (SINGER, 2002) e atende grupos e comunidades de artesãos orientando e qualificando seus produtos, além de promover projetos e ações que agregam e melhoram os seus processos produtivos, tendo em conta a cultura e a comunidade local. 
A Sustentabilidade diz respeito às condições sistêmicas, segundo as quais em nível regional e planetário, as atividades humanas não devem interferir nos ciclos naturais em que se baseia tudo o que a resiliência do planeta permite, e ao mesmo tempo, não devem empobrecer seu capital natural, que será transmitido ás gerações futuras (MANZINI \& VEZZOLI, 2008, p.27). Portanto, compreende-se por Sustentabilidade a capacidade de utilizar ferramentas e estratégias que conciliem as necessidades de desenvolvimento material e econômico com a preservação do meio ambiente, de forma que a biodiversidade e ecossistemas locais e planetários não sejam comprometidos.

Aliado aos princípios da sustentabilidade, o Ecodesign tem como principal objetivo desenvolver produtos, sistemas e serviços compatíveis com o uso consciente de recursos não renováveis e que sejam capazes de minimizar o impacto ambiental causado pela sua produção e ciclo de vida. Segundo MANZINI e VEZZOLI $(2008$, p.18) é "uma aptidão projetual, que concebe os aspectos do projeto, considerando também o impacto ambiental", e (p.91) "considera-se o produto desde a extração dos recursos necessários para a produção dos materiais que o compõem (nascimento) até o último tratamento (morte) desses materiais após o uso do produto".

Complementando essa mesma linha, a Economia Solidária "é uma economia de mercado com base associativista e cooperativista, voltada para a produção, consumo e comercialização de bens e serviços, buscando a valorização do ser humano e não do capital, dentro de um processo de democratização econômica" (SINGER, Paul, 2002). Trata-se de produzir através de práticas econômicas e sociais não competitivas que valorizam a autogestão, a horizontalidade e o cooperativismo, ou seja, um formato organizacional que beneficia todos os seus integrantes, pois não há relações hierárquicas ou exploração de mão de obra, resultando numa igualdade de poder de decisões que reflete no espaço publico, pois contribui para a construção de um meio socialmente justo e sustentável.

\subsection{Associação Cornélia Vlieg e o Armazém das Oficinas}

O Armazém das Oficinas é uma loja localizada em Campinas-SP que serve como marca dos produtos e serviços das oficinas desenvolvidos pelo NOT - Núcleo das Oficinas de Trabalho -, da Associação Cornélia Vlieg, que atua em conjunto com o Serviço de Saúde "Dr. Cândido Ferreira", sediado no distrito de Sousas, da mesma cidade. Foi fundado em 2002 para atender à população de baixa renda que apresenta quadros de doença mental, vulnerabilidade e não tem oportunidade de inserção no mercado formal; nas oficinas, essas pessoas são inseridas no convívio social por meio do trabalho, exercendo sua cidadania e tendo uma oportunidade de trabalho que dificilmente teriam fora dali, além de conseguirem gerar renda e resgatar suas dignidades. O Núcleo conta com 14 oficinas: Culinária Eventos, Culinária Nutrição, Papel Reciclado, Vitral, Construção Civil, Ladrilho Hidráulico, Agrícola, Mosaico, Marcenaria, Serralheria, Vela, Vitral Plano e Gráfica e o Projeto Parceria. A produção de boa parte desses espaços é comercializada no Armazém, e a renda é revertida em bolsa-oficina pelos usuários.

As oficinas da associação interagem em sua produção comprando peças umas das outras para montar produtos completos, como por exemplo estruturas metálicas 
da Serralheria para luminárias na oficina de Vitral, ou mesas de madeira da Marcenaria cujos tampos são feitos pela oficina de Mosaico.

\subsection{Parceria ente o Labsol e a Associação Cornélia Vlieg e Núcleo das Oficinas de Trabalho}

Em agosto de 2015, a coordenação do NOT - Núcleo de Oficinas de Trabalho da Associação Cornélia Vlieg, entidade que trabalha junto ao Serviço de Saúde "Dr. Cândido Ferreira", situado no distrito de Sousas, de campinas, entrou em contato com - Labsol em busca de assessoria, para análise e possível redesign de algumas linhas de seus produtos. Acatando a demanda, o LabSol visitou a associação para observação e registro das técnicas, produtos e propostas da mesma.
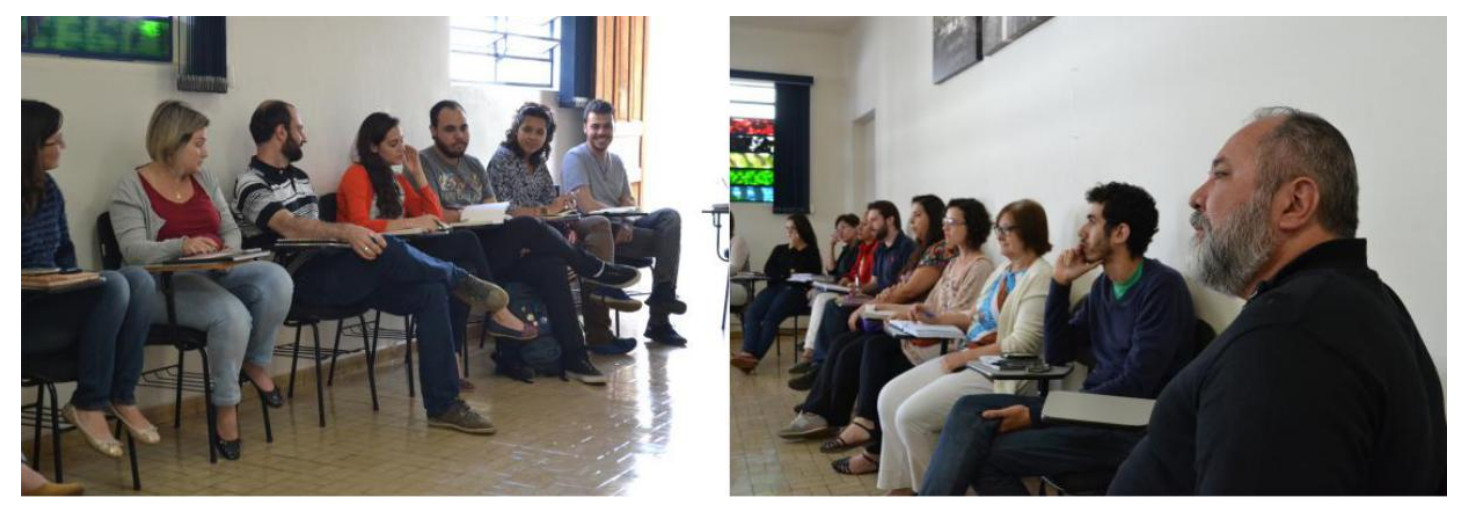

Figuras 1 e 2 - Visita do Labsol na Associação cornélia, Reunião.

Fonte: Fotografias retiradas pelo Labsol no processo da pesquisa.

Uma análise inicial do NOT demonstrou que as oficinas são muito bem estruturadas, com linhas de produtos já segmentadas, e que o principal meio de assessoria do Laboratório seria o de apontar estratégias que unificassem a produção dos diferentes espaços de modo a criar uma identidade local, com eixos temáticos que percorressem todos os artefatos produzidos pela associação.

Levando em consideração que, além do Armazém das Oficinas, boa parte da produção do NOT é levada a grandes feiras de artesanato do país, como a Mega Artesanal e a Gift Fair, a equipe do Labsol partiu de um tema relacionado à região e a outro de maior apelo comercial: Andorinhas e Zodíaco, respectivamente.

Foram desenvolvidos diversos desenhos de silhuetas de andorinhas, que poderiam ser explorados em diversas superfícies que são desenvolvidas no Núcleo, como na oficina de Mosaico, Ladrilho; Já o eixo temático do Zodíaco, o de maior produção, teve dezenas de desenhos prévios anteriores aos designs finais, que poderiam ser aproveitados principalmente pela oficina de Mosaico, visto que foram elaborados pensando na valorização do contorno e na simplicidade das peças utilizadas pelos trabalhadores da área. Além dos desenhos, foram realizadas pesquisas referentes à composição cromática das peças, de modo a auxiliar a criação dos artesãos; a mesma pesquisa foi aberta às outras oficinas do NOT, que poderiam se aproveitar das informações para elaborarem seus próprios artefatos.

Também desenvolvemos produtos para a oficina de vitrais, marcenaria, velas, papel reciclado e ladrilho hidráulico, mas trabalhando com temas diversos. 


\subsection{Oficina de Mosaico}

Quando o projeto Labsol visitou a oficina de mosaicos do NOT, foi possível perceber pelo grupo que sua produção tinha alguns problemas. Entre os artesãos, por exemplo, havia certa dificuldade de criar desenhos harmônicos, não havia bem uma diretriz clara de como eles deviam trabalhar, era apenas necessário que se trabalhasse em temas florais, ou marinhos. Além disso, era presente uma falta de identidade dos trabalhos, tanto entre os próprios mosaicos, como na relação do artesão com a sua obra (com exceção de um indivíduo que desenvolveu uma técnica própria em que se usa o esmeril para curvar peças de forma a deixar algumas acabamentos mais orgânicos), a pesar de terem boa técnica e prática.

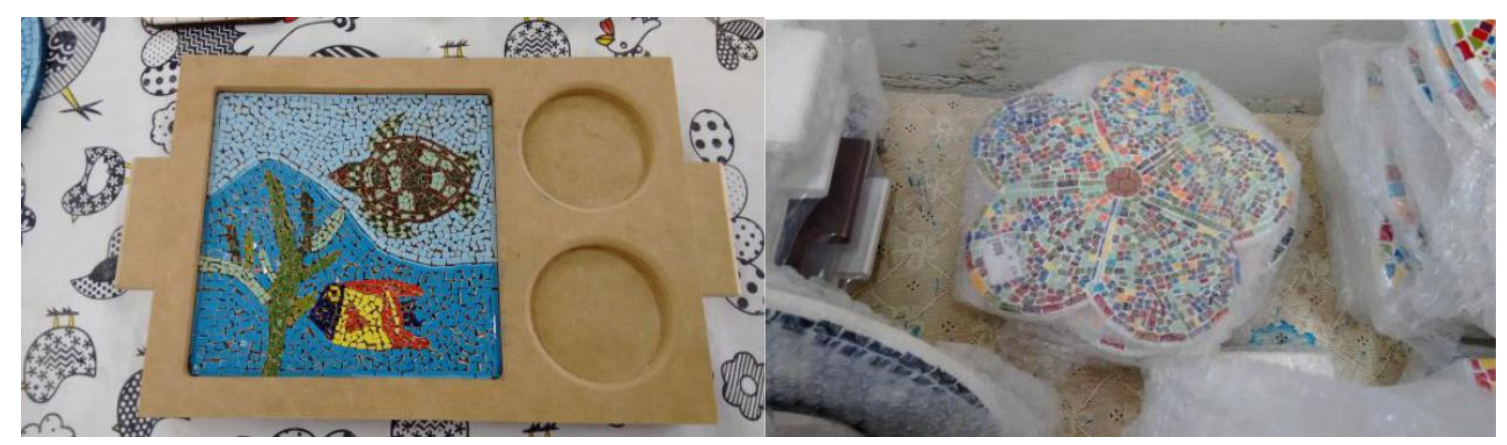

Figuras 3 e 4 - Trabalhos da oficina de mosaico do NOT.

Fonte: Fotografias retiradas pelo Labsol em visita à Associação Cornélia.

Todo esse quadro de questões negativas na produção dos mosaicos, eram contrastantes tanto com a boa técnica que os oficineiros possuíam quanto com a prática adquirida por ser algo que já fazem a anos. Em vista das capacidades dos mosaicistas tomamos como estratégia para a oficina a elaboração de duas coleções de desenhos originais: uma com andorinhas, e outra baseada no Zodíaco. Todas as formas são simples, priorizando o preenchimento mais fácil pelos ladrilhos.

A andorinha é uma ave símbolo da cidade de Campinas, e consideramos esse um fator decisivo para a utilização desse animal como tema, visto que o artesanato sempre tem em si o reflexo do lugar no qual é produzido; assim, sugerimos diversos desenhos que podem ser usados em peças de tamanhos e formatos variados. 


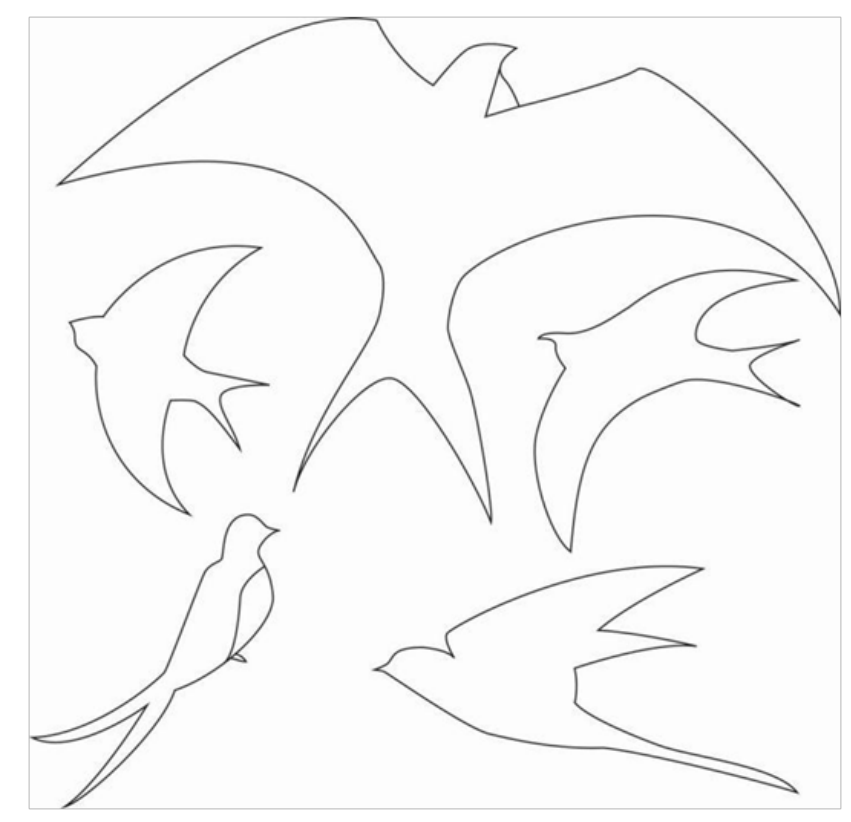

Figura 5 - Desenho de Andorinhas. Fonte: elaborado por integrantes do Labsol;

O tema do zodíaco foi determinado por duas razões: a força que o tema tem atualmente, sendo o zodíaco parte da cultura popular, atraindo diversos segmentos sociais e etários, e a forte ligação com a cultura grega, sendo que os gregos inventaram a técnica do mosaico. Para a linha do zodíaco, além das imagens elaboramos uma tabela de referência com sugestão de cores e motivos, para facilitar a aplicação nas mais diversas peças produzidas pela oficina, desde bandejas a mesas com muitos motivos diferentes.

Esta tabela tem apenas os detalhes principais, levados em conta apenas como sugestão quando forem compostos nos objetos; não é uma regra específica de que as cores denominadas sejam as mesmas utilizadas nas peças finais, até mesmo porque tradições diferentes apontam para cores e características diferentes.

Apresentamos, assim, aquelas que são mais comumente conhecidas no Brasil, e que podem servir de inspiração ao elaborar novos projetos utilizando essa temática.

\begin{tabular}{|l|l|l|l|l|l|}
\hline$\#$ & Signo & Período & Elemento & Cores & $\begin{array}{l}\text { Característica } \\
\text { s }\end{array}$ \\
\hline $\mathbf{1}$ & Áries & $21 / 03-21 / 04$ & Fogo & $\begin{array}{l}\text { Vermelho, } \\
\text { branco, preto }\end{array}$ & $\begin{array}{l}\text { Assertivo, } \\
\text { Impulsivo }\end{array}$ \\
\hline $\mathbf{2}$ & Touro & $22 / 04-21 / 05$ & Terra & Verde, rosa & $\begin{array}{l}\text { Estável, } \\
\text { Teimoso }\end{array}$ \\
\hline $\mathbf{3}$ & Gêmeos & $22 / 05-21 / 06$ & Ar & Amarelo & $\begin{array}{l}\text { Versátil, } \\
\text { Adaptável }\end{array}$ \\
\hline $\mathbf{4}$ & Câncer & $22 / 06-22 / 07$ & Água & Branco, cinza & $\begin{array}{l}\text { Espontâneo, } \\
\text { Protetor }\end{array}$ \\
\hline $\mathbf{5}$ & Leão & $23 / 07-22 / 08$ & Fogo & Dourado & $\begin{array}{l}\text { Magnético, } \\
\text { Expressivo }\end{array}$ \\
\hline $\mathbf{6}$ & Virgem & $23 / 08-22 / 09$ & Terra & $\begin{array}{l}\text { Marrom, azul- } \\
\text { marinho }\end{array}$ & $\begin{array}{l}\text { Perfeccionista, } \\
\text { Analítico }\end{array}$ \\
\hline $\mathbf{7}$ & Libra & $23 / 09-22 / 10$ & Ar & Azul, verde- & Equilíbrio, \\
\hline & & & & esmeralda & Parceiro \\
\hline $\mathbf{8}$ & Escorpião & $23 / 10-22 / 11$ & Água & $\begin{array}{l}\text { Verde, azul- } \\
\text { esverdeado }\end{array}$ & $\begin{array}{l}\text { Intenso, } \\
\text { Apaixonado }\end{array}$ \\
\hline $\mathbf{9}$ & Sagitário & $23 / 11-22 / 12$ & Fogo & Roxo, azul & Viajante,
\end{tabular}




\begin{tabular}{|l|l|l|l|l|l|} 
& & & & & Atirado \\
\hline $\mathbf{1 0}$ & Capricórnio & $23 / 12-20 / 01$ & Terra & $\begin{array}{l}\text { Preto, cinza, } \\
\text { marrom }\end{array}$ & $\begin{array}{l}\text { Disciplina, } \\
\text { Paciência }\end{array}$ \\
\hline $\mathbf{1 1}$ & Aquário & $21 / 01-19 / 02$ & Ar & Violeta & $\begin{array}{l}\text { Independente, } \\
\text { Incomum }\end{array}$ \\
\hline $\mathbf{1 2}$ & Peixes & $20 / 02-20 / 03$ & Água & Verde-claro, azul & $\begin{array}{l}\text { Espiritual, } \\
\text { Finalizador }\end{array}$ \\
\hline
\end{tabular}

Figura 5 - Tabela para criação de desenhos do Zodíaco.

Fonte: Figura elabora por membros do Labsol.

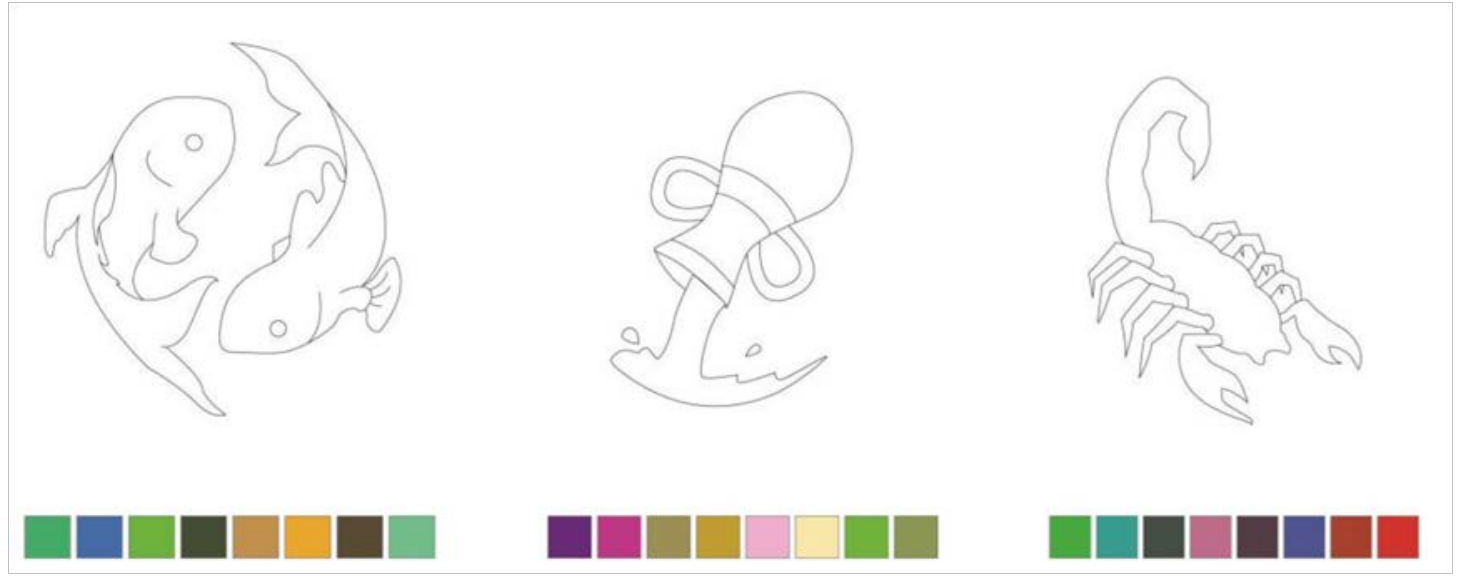

Figuras 6, 7 e 8 - Desenhos vetorizados para o desenvolvimento de peças em mosaico.

Fonte: Imagens desenvolvidas pelo Labsol durante o processo da pesquisa.

\subsection{Metodologia}

Trata-se de um trabalho empírico de caráter prático, onde após revisão bibliográfica, envolvendo áreas como o design, pesquisa cultural e de mercado, e química/ambiental, tendo como base conceitual a Sustentabilidade, o Ecodesign, o design social e a Economia Solidária, utiliza-se a Metodologia do Projeto em Design do Produto (BAXTER, 2011) procurando suprir a demanda da Cooperativa e o desenvolvimento de novos produtos tendo em conta as características socioculturais em que se insere o NOT.

Será utilizada a metodologia de projeto em Design para o desenvolvimento de novos produtos, reformulação dos existentes, nos adaptando aos métodos e processos. O procedimento ocorrerá através da pesquisa empírica com o desenvolvimento de diversos desenhos conciliando os processos de produção e a matéria prima local à demanda de mercado, equalizando as formas, as cores e a técnica, gerando um desenvolvimento sustentável e valorizando os produtores e seus produtos. A partir da experiência acumulada pelo Labsol e pela Associação, podemos antever a produção de objetos mais elaborados de decoração.

Por meio da captação de conhecimento popular, o Labsol busca desenvolver técnica e esteticamente os objetos para lhes agregar maior valor e qualidade. Ao mesmo tempo em que o conhecimento popular serve como base para desenvolver o conhecimento científico aproximando associação e universidade. Devolvendo à sociedade as oportunidades e conhecimentos gerados dentro do meio acadêmico como forma de retribuição ao apoio e confiança creditados a Universidade. 


\section{CONCLUSÃO}

Após visitar a sede do Núcleo das Oficinas (NOT) e o Armazém das Oficinas para conhecer de perto sua produção, o Labsol entendeu melhor sobre os princípios operacionais, aspectos técnicos do grupo e dos materiais utilizados nas linhas de produção.

Uma vez retendo esse repertório técnico e imagético, desenvolvemos desenhos para as produções futuras da oficina. A receptividade às sugestões do LabSol e de nossa forma de trabalho foi muito boa. Os mosaicistas se mostraram satisfeitos por terem recebido desenhos simplificados que foram pensados de acordo com os formatos mais comuns em suas peças. Também foi de grande apreciação o fato de que - laboratório levou em conjunto com os desenhos um esquema de cores, normalmente havia certa dificuldade nesse sentido para escolhê-las pelos oficineiros.

Projetamos para o futuro grandes melhorias na produção das peças e sua aceitação no mercado, atraindo cada vez mais o público-alvo. As ações do Labsol em parceria com a Associação Cornélia Vlieg buscam qualificar suas criações já existentes sugerindo novas possibilidades dentro da realidade do grupo, valorizando a aliança entre design e artesanato e aplicando conceitos de projeto e do tripé Sustentabilidade, Ecodesign e Economia Solidária.

\section{REFERÊNCIAS}

ASSOCIAÇÃO CORNÉLIA VLIEG, Quem Somos . 2016. Disponível na internet por http em: <http://www.armazemoficinas.com.br/site/quem-somos/42-associacao-corneliavlieg-.html>. Acesso em 21 mai. 2016.

BAXTER, Mike . Projeto de Produto. São Paulo: Blucher, 2000.

BORGES, Adélia. Design+Artesanato. São Paulo: Terceiro Nome, 2011.

GOYA, C. R.; ANDRADE, A. B. P.; DOMICIANO, C. L. C.; ROSSI, D. C.; MEDOLA; F. O.; HENRIQUES, F, SILVA, J. P. C., PASCHOARELLI, L. C.; MOURA, M.; RODRIGUES, O. V.; BIGAL, S. M.; BARATA, T. Carnaval, Cultura Popular e Design - Uma Experiência de Extensão Universitária em Design In: Ensaios em Design - Práticas Interdisciplinares.1 ed. Bauru: Canal 6 Editora, 2014, p. 136-156.

MANZINI, E.; VEZZOLI, C. O Desenvolvimento de Produtos Sustentáveis. São Paulo: USP. 2008.

MANZINI, Ezio; VEZZOLI, Carlo, trad. CARVALHO, Astrid de. O Desenvolvimento de Produtos Sustentáveis: os requisitos ambientais dos produtos industriais. São Paulo: EDUSP, 2002.

SINGER, Paul. Introdução à Economia Solidária. São Paulo: Fundação Perseu Abramo, 2002. 